This essay is part of IJARBM's special issue

"Contemporary Applied Business Research

in Light of Standard Academic Literature".

\title{
Digital Transformation as a Tool for Organizational Change and Value Creation
}

\author{
Ethan Aboiron \\ ethan.aboiron@neofaculty.org \\ Neofaculty Lab, Barcelona, Spain \\ Jeremie Aboiron \\ aboiron@neofaculty.org \\ Neofaculty Lab, Barcelona, Spain \\ https://doi.org/10.51137/ijarbm.2022.3.1.4
}

\begin{abstract}
The impact of digital transformation in organizations can be approached from different perspectives. In this article we will focus on the issue of organizational change and value creation through digital transformation. We will see that digital transformation affects organizations as well as their structure. We will observe the impact of this through theories of structural contingency. Beyond the organizational change, we will see that the digital transformation will impact the primary functions of the organization, the support functions, and the decision-making processes through informational issues. The digital era opens up new opportunities for organizations in terms of manufacturing processes, automation, and decision-making.
\end{abstract}

Keywords - Digital Transformation, Organizational Theory, Strategy, Value Creation, Opportunity, Change Management

\section{Factors of Organizational Evolution}

The creation of value through the digital transformation of organizations can be observed through the prism of structural contingency theories. Indeed, we can consider digital transformation as the result of both internal and external structural contingency. Many of these theories are normative, which makes them the clearest point of articulation between organizational theory and corporate strategy.

\subsection{Internal Contingency}

Concerning internal variables, we can look at Aldrich (1976) which is much criticized by Argyris (1978) and Crozier (1977). His theory highlights that with size, diversification, differentiation and specialization are inevitable, but that management must also grow in order to maintain a sufficient degree of control in the fundamentals. 
According to Greiner (1990) there are four phases in the life cycle of organizations, namely:

- Entrepreneurial (creativity, innovation or creation of a niche)

- Collective (strong cohesion and involvement in the organization)

- Formalization and control (stability and institutionalization)

- Structure development and adaptation.

The last phase of maturity leading to decline and disappearance. Each phase has different organizational phenomena and should be analyzed on evaluation criteria specific to that phase. Digital transformation can be part of several phases, but most often it is in the so-called adaptation phase.

Stinchcombe (1965) and Mintzberg (1979) agree in describing a link between the current structure of certain organizations and the period in which the types of industry to which they belong appeared and not the age of these organizations. Stinchcombe counts 4 periods of industry: the pre-factory model (farm, construction), early 19th century (textiles, banking), railroad (railways, mining) and modern (air transport, automobiles). Mintzberg, extends this analysis and defines a 5th period (aerospace, consultants).

\subsection{External Contingency}

Burns and Stalker (1961) study twenty Scottish and English companies to evaluate the state of environmental conditions in relation to the technology to be employed and the product market. They obtain five types of environment in a continuum, with mechanistic and organic structures at the extremes. The mechanistic structures correspond in fact to the rational bureaucracy of the rational theory but with its dysfunctions. All firms are rather close to one pole or the other and neither model is superior to the other. Problems arise when an organization chooses a structure that is not adapted to its environment or when the environment changes.

Emery and Trist (1963) address the issue of the increasing complexity of the environment. They identify four categories of environments:

- random placid: Events that can occur are always more or less the same but occur randomly. Trial and error is used on a local basis.

- clustered and fairly stable: The events that can occur are always more or less the same, are connected, precisely distributed and not random. Therefore a good knowledge of the environment is essential.

- reactive moving: Oligopolistic market organization. The company must seek its own optimal location, consider the movements of others and move accordingly. (large automotive companies)

- turbulent field: Unstable and uncertain environment and as the elements are disconnected and independent and in constant movement the consequences of decisions are less and less predictable. Increasingly frequent environment, which pushes the company to continually re-evaluate its relationships. 
Lawrence and Lorsch (1967) go a step further in their analysis by addressing the issue of diversified adaptation to the environment, integration and differentiation. They studied 10 organizations in 3 industries in the 1960s. The three industries were differentiated on the basis of environmental competitiveness, product life cycle and pace of innovation. The innovative character of their research lies in the fact that neither the environment nor the firm is considered as homogeneous and that each part of the firm acts in a part of the environment. The most successful firms were those that had a degree of differentiation corresponding to the uncertainty of their environment, accompanied by an appropriate degree of integration and relevant resolution procedures. According to them, the more turbulent the environment, the more differentiated the organizations must be, and the more diversified they are, the more likely there is to be conflict between departments. An organizational structure is contingent on external or internal data that may vary, but it is not homogeneous. The environment can present different facets to different parts of the organization.

\subsection{The Influence of Technology on Organization}

Each organization appropriates technology according to its sector of activity, its history, its size, etc. According to Woodward (1965), the key factor in the disparity between organizations is technological complexity. He explains that it is not the size of the organization but the technological complexity that influences the control of the production process and the predictability of results. Consequently, the traditional theories are adapted to mass production firms, but for other firms it is the technology in place that determines the structure to be adopted.

Objectives and structure are therefore the dependent variables of the independent variable, technology. What Perrow (1967) explains to us, is that organizations are operating systems whose purpose is to change raw materials and not to achieve cooperative decisions or processes. The latter are consequences of the central phenomenon. This means that technology is not there to lead to decisions but to improve the production process.

According to Chandler (1962), based on a study of the history of the largest American companies from 1909 to 1959, the structure follows the established strategy to adapt to the external environment. Child (1972) refines the concept of strategic choice for the organization. He believes that the choices of goals and courses to achieve them are made by the dominant coalition in the organization, which may be the owners, founders, or any other group controlling the management. A company can redefine itself and its markets if it identifies its structures as the cause of poor performance. Moreover, the relationship with the firm's environment is one-to-one and finally the perception and evaluation of the environment by the managers must be separated from the objective characteristics of the environment. 


\section{Value Chain and Digital Transformation}

Strategic capability can be examined through many tools: standardization, value chain, activities mapping and the SWOT matrix. What we are interested in here is Porter's value chain (1986). It allows us to identify the activities that contribute to the creation of value, which will allow the organization to differentiate itself from competitors and to gain a competitive advantage. Thus the organization's offer can be valued by the clients. The chain is composed of primary functions (located at the bottom of the chain) and secondary functions (located at the top of the chain). Thus these functions must give the organization the possibility to create a sufficient margin.

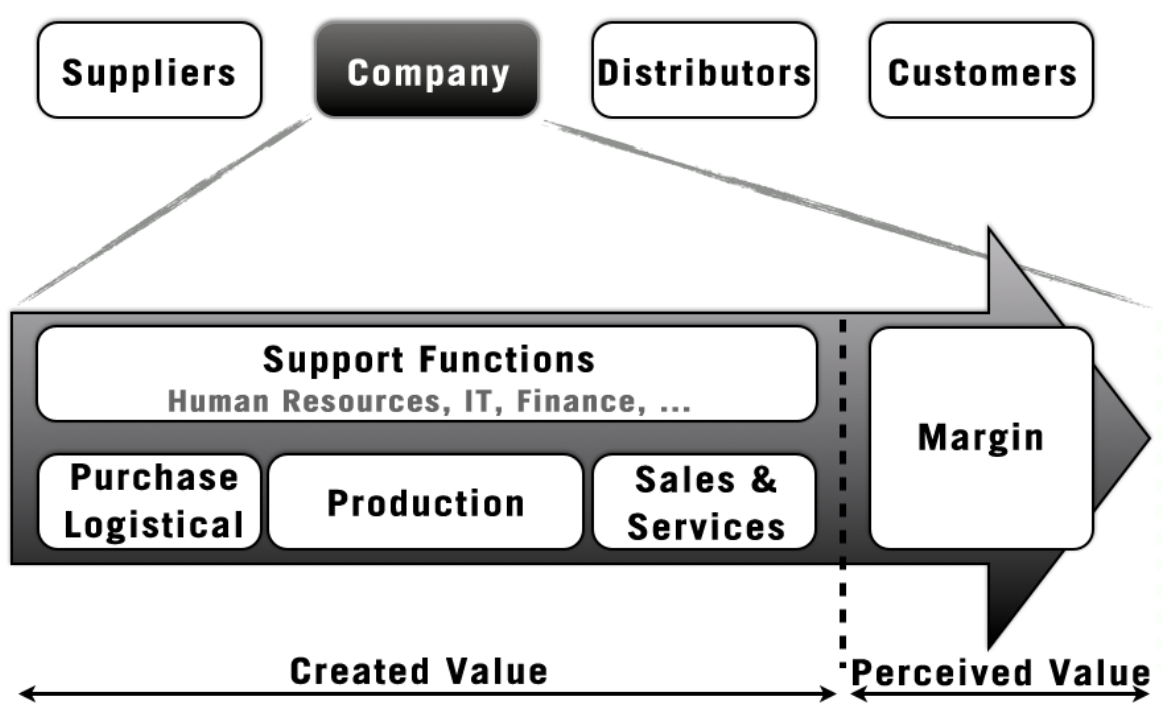

Figure 1: Adapted Value Chain (Porter 1980)

The analysis of the value chain gives us a large overview of the organization's strategic capability. However, contrary to the business model, the value chain is " an ex post analysis tool » (Warnier et al, 2004).

Digital transformation can have an impact and represent a challenge on all primary activities, those directly producing value for the organization, and also on support activities, not directly creating value but allowing primary activities to be more effective and efficient.

\subsection{The Role of Digital Technology on Value Creation}

In our view, digital transformation is crucial in the so-called adaptation phase as defined by Greiner. In addition to Stinchcombe's arguments about the role of industry maturity as a determinant in technology appropriation. We argue that the maturity of the technology also has an impact on its appropriation and use by organizations. As we have seen with Lawrence and Lorsch, external contingencies in the environment are the triggers for digital 
transformation and the appropriation of new technologies. This is due to the need for organizations to maintain a competitive advantage and therefore to respond to all the key success factors of their sector.

The competition on the market of goods and services is tough and organizations are forced to find solutions to survive in such a hostile environment. This is why it is important for their future to create their own competitive advantage in order to stand out from their competitors. This means creating a temporary advantage by having a particular resource that will produce a greater efficiency compared to other competitors in the same markets. The concept of competitive advantage comes from Michael Porter (1985) in his work on Competitive Advantage. Following Competitive Strategy: Techniques for Analyzing Industries and Competitors (1980) in which he examined industry, Porter chose to focus on companies in this work (which we will extend to organizations in general here). Except in case of mono-activity, it is important to note that the internal analysis must focus on the target Strategic Business Unit. Indeed, the competitive advantage can be obtained in a very different way according to the Strategic Business Unit of the group. From then on, we consider SBU as owning a competitive advantage « when the difference between the value it creates for its customers and the cost involved in this is at the same time positive and higher than the equivalent difference of the competitors » (Johnson et al, 2011).

\subsection{Competitive Advantage Through Cost}

This advantage will gradually be set up as the company acquires an efficient productivity. This notion emphasizes the theory of learning from experience. Indeed the employees will be more and more experienced over time; the tools and methods will be tested and improved, etc. The work processes will be assimilated and optimized, thus creating an increase in productivity. It is the officer Wright who demonstrated this effect by showing that the total production of airplanes was increasing as workers became more qualified and as their professional experience in the field increased. Thus the company was saving up to $20 \%$ just from this experience effect. Today we can accept that the digital transformation can offer the same advantage thanks to technology. For example, the use of $3 \mathrm{D}$ in the process of Toyota car manufacturing completely change the processes and the performance of Toyota.

As a result, this cost reduction will create a barrier around the activity sector of the company, therefore restricting other competitors to a higher production cost since they are not benefiting from this experience effect. The main risk of the experience effect is that it makes production too rigid. The product would become less adaptable to the needs and expectations of the customers. Here, we can make a link with the concept of dynamic capability. To sustain one's competitive advantage, it is very important to ensure the adaptation of this strategic capability. One example of this type of situation is the production of the Ford Model T. All the products were identical and households got tired of it quickly. However, it should be noted here that the 
cost reduction observed is not only a result of experience effect but also a result of the economies of scale and of the company's innovation process.

\subsection{Competitive Advantage Through Differentiation}

Porter mentioned two types of differentiations, the first according to the products and the second according to cost. Product differentiation is made through the creation of a competitive advantage on the specialization of the offer. Thus, the organization will escape from a direct competition through price since its supply becomes small compared to that of its competitors. Product differentiation through prices allows the company to establish itself with a favorable position on the market. Competitors cannot afford to reduce their prices that much; therefore all customers go to the company offering the cheaper similar item. The differentiation strategy can be divided into four major strategies: improvement strategy, low cost strategy, limitation strategy and specialization strategy. The digital transformation can create a competitive advantage through the consumer experience with the ability to personalize and create unique products. As an example we can refer to the company Book on Demand which prints books on demand and eliminates the concept of stock.

\section{Conclusion}

We understand through this work that we do not completely agree with Perrow when he states that transformation is not about enabling decision making. For we believe that today technology is involved in the decisionmaking process at all levels of the organization. Tounkara (2020) describes three essential roles of digital transformation in organizations. Two roles related to Perrow's affirmations which are automation and process transformation. These roles are clearly applicable to the raw material of the business and direct value creation. However, a third role stands out: the informational role. This last point is new compared to previous research on technology and organization. Indeed, it raises questions about knowledge management, both business and buyer knowledge, about organizational learning as a consequence of this knowledge creation, and also about the ability of organizations to automate a certain number of operational and/or strategic decisions.

\section{$4 \quad$ References}

Aldrich, H. E., \& Pfeffer, J. (1976). Environments of organizations. Annual

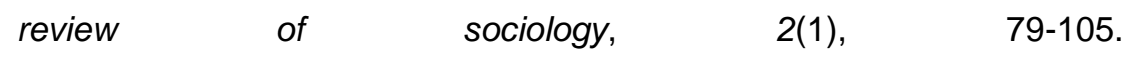
https://doi.org/10.1146/annurev.so.02.080176.000455 
Argyris, C. (1978). Organization Design.

Burns, T., \& Stalker, G. M. (1961). The management of innovation. Tavistock, London, 120-122.

Chandler, A. D. (1962). Strategy and structure: Chapters in the history of the industrial empire.

Child, J. (1972). Organizational structure, environment and performance: The role of strategic choice. sociology, 6(1), 1-22. https://doi.org/10.1177/003803857200600101

Crozier, M., \& Friedberg, E. (1977). L'acteur et le système.

Emery, F. E., \& Trist, E. L. (1965). The causal texture of organizational environments. Human relations, 18(1), 21-32. https://doi.org/10.1177/001872676501800103

Hanks, S. H. (1990). The organization life cycle: Integrating content and process. Journal of small business strategy, 1(1), 1-12. https://libjournals.mtsu.edu/index.php/isbs/article/view/218

Lawrence, P. R., \& Lorsch, J. W. (1967). Organization and environment managing differentiation and integration.

Mintzberg, H. (1979). The structure of organizations: A synthesis of the research. Prentice-Hall.

Perrow, C. (1967). A framework for the comparative analysis of organizations. American sociological review, 194-208. https://doi.org/10.2307/2091811

Porter, M. E. (1980). Competitive strategy: techniques for analyzing industries and competitors. 
Porter, M. E. (1985). Competitive advantage: creating and sustaining superior performance. 1985. New York: FreePress.

Porter, M. E. (1986). Changing patterns of international competition. Califor$\begin{array}{lll}\text { nia } & \text { Management } & \text { 28(2), }\end{array}$ https://doi.org/10.2307/41165182

Stinchcombe, A. L. (1965). Organizations and social structure. Handbook of organizations, 44(2), 142-193.

Tounkara, T. (2020). Automatisation Robotisée des Processus (RPA): quels défis pour la transformation numérique des entreprises?. Approches Theoriques en Information Communication, (1), 95-118. https://doi.org/10.3917/atic.001.0095

Warnier, V., Lecocq, X., \& Demil, B. (2004, June). Le business model: l'oublié de la stratégie. In présenté à la 13ème Conférence Internationale de Management Stratégique (pp. 2-4).

Woodward, J. (1965). Industrial Organization: Theory and Practice. Oxford. 